Accepted manuscript of article accepted for publication in Current Addiction Reports.

\title{
Epidemiological challenges in the study of behavioral addictions: A call for high standard methodologies
}

Authors: Hans-Jürgen Rumpf $\mathrm{PhD}^{1}$, Dominique Brandt $\mathrm{MSc}^{1}$, Zsolt Demetrovics $\mathrm{PhD}^{2}$, Joël Billieux $\mathrm{PhD}^{3}$, Natacha Carragher $\mathrm{PhD}^{4}$, Matthias Brand $\mathrm{PhD}^{5}$, Henrietta Bowden-Jones $\mathrm{MD}^{6}$, Afarin Rahimi-Movaghar $\mathrm{MD}^{7}$; Sawitri Assanangkornchai $\mathrm{MD}^{8}$, Renata Glavak-Tkalic $\mathrm{PhD}^{9}$, Guilherme Borges $\mathrm{PhD}^{10}$, Hae-Kook Lee ${ }^{11} \mathrm{MD}$, Florian Rehbein $\mathrm{PhD}^{12}$, Naomi A. Fineberg $M^{13}$, Karl Mann MD ${ }^{14}$, Marc N. Potenza MD, PhD ${ }^{15}$ Dan J. Stein $M^{16}$, Susumu Higuchi $M D^{17}$, Daniel King $\mathrm{PhD}^{18}$, John B. Saunders $\mathrm{MD}^{19}$ and Vladimir Poznyak MD PhD ${ }^{20}$ ${ }^{1}$ University of Lübeck, Department of Psychiatry and Psychotherapy, Center for Integrative Psychiatry, Research Group S:TEP, Lübeck, Germany

${ }^{2}$ Institute of Psychology, ELTE Eötvös Loránd University, Budapest, Hungary

${ }^{3}$ Addictive and Compulsive Behaviours Lab, Institute for Health and Behaviour, University of Luxembourg, Esch-sur-Alzette, Luxembourg

${ }^{4}$ Department of Mental Health and Substance Abuse, WHO Headquarters, Geneva, Switzerland

${ }^{5}$ General Psychology: Cognition and Center for Behavioral Addiction Research (CeBAR), University of Duisburg-Essen, Germany

${ }^{6}$ Central North West London NHS Trust and Division of Brain Science, Imperial College London, London, UK

${ }^{7}$ Iranian National Center for Addiction Studies, Tehran University of Medical Sciences, Tehran, Iran

${ }^{8}$ Epidemiology Unit and Centre for Alcohol Studies (INCAS), Faculty of Medicine, Prince of Songkla University, Hat Yai, Songkhla, Thailand

${ }^{9}$ Institute of Social Sciences Ivo Pilar, Zagreb, Croatia

${ }^{10}$ National Institute of Psychiatry, Mexico City, Mexico 
Accepted manuscript of article accepted for publication in Current Addiction Reports.

${ }^{11}$ Department of Psychiatry, College of Medicine, The Catholic University of Korea, Seoul, South Korea

${ }^{12}$ Criminological Research Institute Lower Saxony, Hannover, Germany

${ }^{13}$ University of Hertfordshire, University of Cambridge, and Hertfordshire Partnership University NHS Foundation Trust, Hatfield, UK

${ }^{14}$ Central Institute of Mental Health, University of Heidelberg, Mannheim, Germany

${ }^{15}$ Departments of Psychiatry and Neuroscience, Child Study Center, Yale University School of Medicine, and the Connecticut Council on Problem Gambling and Connecticut Mental Health Center, New Haven, USA

${ }^{16}$ Department of Psychiatry and Mental Health, SA MRC Unit on Risk \& Resilience in Mental Disorders, University of Cape Town, South Africa

${ }^{17}$ National Hospital Organization Kurihama Medical and Addiction Center, Yokosuka, Kanagawa, Japan

${ }^{18}$ School of Psychology, The University of Adelaide, Adelaide, Australia

${ }^{19}$ Centre for Youth Substance Abuse Research, The University of Queensland, Brisbane, Australia

${ }^{20}$ Department of Mental Health and Substance Abuse, WHO Headquarters, Geneva, Switzerland 
Accepted manuscript of article accepted for publication in Current Addiction Reports.

Correspondence:

PD Dr. Hans-Jürgen Rumpf

University of Lübeck, Department of Psychiatry and Psychotherapy, Center for Integrative Psychiatry, Research Group S:TEP

Ratzeburger Allee 160, 23562 Lübeck

Phone: +4945150098751

Fax: +4945150098754

Email: hans-juergen.rumpf@uksh.de

Keywords: behavioral addiction; epidemiology; surveys; assessment; recommendation; random error; systematic error 
Accepted manuscript of article accepted for publication in Current Addiction Reports.

\section{Abstract}

Purpose of review: The $5^{\text {th }}$ edition of the Diagnostic and Statistical Manual of Mental Disorders (DSM-5) categorizes gambling disorder in the section on substance-related and addictive disorders and the $11^{\text {th }}$ revision of the International Classification of Diseases (ICD11 ) includes both gambling and gaming disorder as disorders due to addictive behaviors. However, there is less evidence for other putative behavioral addictions. This review focuses on requirements for epidemiological studies of disorders that may be considered as behavioral addictions and compares the current state of research with principles of sound epidemiological research.

Recent findings: In studies of behavioral addictions, samples are often quite small, which may lead to increased random error. The lack of sound assessment tools - particularly the lack of agreed-upon diagnostic criteria and standardized diagnostic interviews - may also increase systematic error. Other concerns related to systematic bias include the use of convenience samples, lack of pro-active recruitment, inadequate assessment of confounding variables, and a dearth of representative and longitudinal studies.

Summary: This review recommends that future studies of putative behavioral addictions should more closely adhere to methodological standards of epidemiological research to reduce random and systematic error. Specific recommendations are detailed to advance epidemiological research in this area with the aim of improving the evidence base and generating more refined public health recommendations and policies.

Introduction

While multiple behaviors have been identified as potentially being addictive, for many there is a lack of empirical evidence that they may develop into a disorder. Some are based on a solid evidence, while for others the literature is scanty and unconvincing. Of the proposed behavioral addictions, only gambling disorder and gaming disorder have been identified as 
Accepted manuscript of article accepted for publication in Current Addiction Reports.

valid conditions in the main psychiatric nomenclature systems. Gambling disorder has been accepted as a diagnostic entity for some decades and was formerly named "pathological gambling". It was moved from the section on impulse control disorders to the section on substance-related and addictive disorders in DSM-5 [1]. Gambling disorder is a condition in the section of disorders due to addictive behaviors in the $11^{\text {th }}$ revision of the International Classification of Diseases (ICD-11) [2].

With respect to gaming, Internet Gaming Disorder was included in section III of DSM-5 as a condition requiring further study and gaming disorder was included in the section of disorders due to addictive behaviors in ICD-11 [1]. This decision of the WHO working groups and advisory bodies responsible for ICD-11 development was based in part on a series of annual expert meetings on the public health implications of behavioral addictions held under the auspices of the World Health Organization (WHO) since 2014. Careful consideration of the existing literature by 66 researchers from 25 countries resulted in a conclusion that gaming disorder is an independent behavioral disorder and that a meaningful proportion of the general population suffers from this condition and exhibits functional impairment [3, 4].

Besides gambling and gaming, evidence for other putative behavioral addictions is more limited. Multiple studies use an umbrella construct of "internet addiction," covering activities such as gaming, social network use, pornography viewing, or online buying or shopping. Although the term internet addiction is relatively non-specific and so may have conceptual problems [5], it may well point to an array of prevalent and problematic behaviors, and research on the topic has been rapidly growing. On the other hand, some putative conditions (e.g., "love addiction") seem speculative, and are based on very few publications [6].

The issues raised in this review are of relevance for the precision and validity of epidemiological studies of behavioral addictions, and so ultimately for nosological and public health decision-making. Our focus is on what may be considered as emerging conditions; therefore, we will not include gambling disorder given the long history of high-quality research on this condition which encompasses epidemiological studies [e.g. 7, 8, 9]. Since 
Accepted manuscript of article accepted for publication in Current Addiction Reports.

the largest body of literature has been published on gaming disorder or "internet addiction," we will focus on these conditions. However, issues discussed may have relevance for other putative behavioral addictions.

What are the general aims of epidemiological studies?

In general, epidemiology is defined as investigations on the distribution and determinants of health conditions in populations or subgroups [10]. Such investigations may be descriptive or analytical in nature. Two of the most important measures of descriptive epidemiology are prevalence (proportion of a population affected at a particular point in time) and incidence (proportion of new cases among unaffected individuals during a specific period of time). Such measures are needed to estimate the public health implications of disorders and the need for treatment and prevention. These measures are important to compare across countries or regions and to examine changes over time and estimations of trends and future developments.

Analytical epidemiology goes on to consider potential risk factors and their interactions. Risk factors may be related to individual (internal) or environmental (external) variables and may operate at macro (e.g. from society) and micro (e.g. genetics) levels [10]. Knowledge of risk factors is important to inform prevention measures and treatment approaches. In addition, epidemiological findings provide the basis for developing and improving theoretical models of behavioral addictions. One current approach is the Interaction of Person-Affect-CognitionExecution (I-PACE) model [11]. The accuracy of this and other models depends on the precision and validity of the potential risk factors identified in epidemiological studies.

A sample is always a small part of reality, and thus the reliability and validity of data are often limited. As Kenneth Rothman stated: "An epidemiological study is properly viewed as an exercise in measurement, with accuracy as the goal. Design strategies are intended to reduce the sources of error, both systematic and random. Reduction of random error improves the precision of the measurement, whereas reduction of systematic error improves the validity of measurement" [12; p. 99]. 
Accepted manuscript of article accepted for publication in Current Addiction Reports.

Random error refers mainly to the process of selecting study subjects (sampling) and is often called sampling error. Random error is related to sample size, magnitude of effect, disease rate, and the relative size of the compared groups [12]. Systematic error is related to internal validity and depends on the accuracy of information on the samples under study. Ways of increasing internal validity include: (1) using accurate instruments and (2) undertaking steps to reduce the occurrence of selection bias, information bias (e.g. recall bias), and biases relating to confounding (two factors being associated). External validity indicates how generalizable findings are to other populations. External validity may be improved by increasing representativeness by careful sample selection and use of statistical weightings so that the sample is representative of the surveyed population (when possible).

Population-based epidemiological surveys are typically the most comprehensive and useful sources of information. In particular, longitudinal studies investigating the natural history of a disease/disorder may provide a wide range of information on incidence, average duration, severity distribution, remission and case fatality. Epidemiological surveys may cover the spectrum of severity and represent a random sample of those affected in the population, and the results obtained may be representative of the population and not just a particular setting; thus, they may allow considerable generalization.

With these considerations in mind, we will examine current epidemiological knowledge and methods in the context of behavioral addictions, and specifically gaming disorder.

How accurate are the epidemiological data on behavioral addictions?

In general, the quality of epidemiological studies in the area of behavioral addictions is often below standards that have been employed in studies of other psychiatric disorders. For example, at the time of writing, there are few published nationally representative general population studies on behavioral addictions using sound diagnostic methods. Several notable exceptions in the United States would include the National Epidemiologic Survey on Alcohol and Related Conditions (NESARC) [13] and National Comorbidity Survey Replication (NCS- 
Accepted manuscript of article accepted for publication in Current Addiction Reports.

R) [14], both of which assessed DSM-IV pathological gambling but not gaming disorder. With respect to gaming disorder, the field has often relied on small, convenience and online samples of students, children, adolescents or adults. However, the quality of studies often differs [15]. Below, we discuss key epidemiological principles, the extent to which they are present in existing studies, and their importance.

\section{Random error}

Multiple epidemiological studies in the area of behavioral addictions are based on small sample sizes which increases the probability of random error. The magnitude of effects found in studies on behavioral addictions and mental disorders often range between small to medium and the disease rate has been suggested to be at the lower level. Prevalence estimates for gaming disorder and related conditions differ widely and range from $0.8 \%$ to $26.7 \%$ for "internet addiction" according to one review [16] and from $0.7 \%$ to $27.5 \%$ for gaming disorder in another review [17]. A meta-analysis including 16 studies of gaming disorder in adolescents found a pooled estimate of $4.6 \%$ [15]. In sum, expectable effect sizes and disease rates highlight the need for large, representative samples from multiple jurisdictions.

Based on these observations, many empirical studies of putative behavioral addictions are flawed by random error limitations. In general, the accuracy of findings may be increased by replications in other studies/settings and random error may be decreased by conducting meta-analyses. As noted above, a meta-analysis of the prevalence of gaming disorder in adolescents has been conducted recently [15]. However, the precision of findings in metaanalyses depends on the quality of studies included.

\section{Systematic error}

As described above, systematic error relates to internal as well as external validity. When focusing on internal validity, the accuracy of measurements in the area of behavioral 
Accepted manuscript of article accepted for publication in Current Addiction Reports.

addictions warrants consideration. For this purpose, the behavior under study should be defined precisely. Validity may be increased by avoiding "umbrella terms" like "internet addiction" that encompass different behaviors such as gaming, social network use and others. In addition, in order to establish a disorder, functional impairment should be evident, which is - for example - the case for gaming disorder [18, 4, 3]. Putative new behavioral addictions should be justified by evidencing functional impairment. In addition, it has to be taken into account that functional impairment depends on age and measurements should be adjusted accordingly. In young age groups, a delay of mental developmental goals should be considered as a significant impairment.

With respect to the assessment of specific putative behavioral addictions, the number of instruments is large, and the tools may relate to different theories, models or concepts [19]. Two reviews of "internet addiction" in 2014 identified 21 [20] and 45 assessment tools [21], respectively. Of the 45 instruments found in the latter review, only 17 were evaluated more than once. Focusing more specifically on gaming disorder, 18 instruments were identified by King et al. [22] in a review published in 2013. The authors highlighted multiple limitations including the inconsistent coverage of core addiction indicators, a lack of agreement or scientific basis for cut-off scores, questionable dimensionality, and inadequate data on predictive validity and inter-rater reliability. Since the publication of DSM-5, multiple new instruments have been developed that are based on criteria for internet gaming disorder [e.g. 23, 24-28].

All assessment tools found in the above reviews are based on questionnaires, whereas fully structured and standardized interview studies are rare [29]. Most questionnaires used in epidemiological studies may be regarded as screening instruments which tend to overestimate prevalence rates [30]. In other words, the marked differences in prevalence estimates between studies $[17,15,16]$ may be greatly influenced by the use of different tools and thresholds. In addition, differences may relate to different population groups under study and different timeframes used (e.g. lifetime, 12-month, 30-day). One study found substantial 
Accepted manuscript of article accepted for publication in Current Addiction Reports.

discordance between self-report data and clinical diagnosis of Internet Gaming Disorder [31] which highlights the limits of questionnaire data in surveys.

With respect to limiting selection bias as another approach for increasing internal validity, it should be emphasized that many studies use convenience samples (e.g., online surveys); this situation represents a serious concern. Such samples differ from the general population and such studies may lead to distorted findings as a consequence of sample selection bias $[32,33]$. This consideration is not only related to prevalence estimates but also to potential risk factors. Similar concerns relate to samples recruited through media solicitation [34]. Few studies are based on general populations or well described, representative subpopulations recruited pro-actively $[17,15,20]$. In addition, most studies are cross-sectional, which may introduce information bias (such as recall bias), and many do not adequately address potentially confounding factors by assessing relevant variables in a sound manner - e.g. cooccurring disorders - and controlling for them in respective analyses. Finally, external validity in many epidemiological studies of gaming disorder and internet addiction is limited by the use of non-representative samples. Therefore, results may not be generalized.

\section{Conclusions}

Random error and systematic error differ between conditions under study. Many current studies of putative behavioral addictions are limited by weak theoretical underpinnings, poor assessment instruments, selective samples, exclusively cross-sectional observations, incomplete control of confounding, and non-representative approaches [35]. Conditions like gambling disorder and gaming disorder have been better studied and are more evidencebased. Currently, there is a dearth of sound epidemiological studies on many other putative behavioral addictions. Studies that have been conducted to date have often lacked precision, in part due to the relative infancy of the field. Related to this, agreed-upon criteria and standard assessment tools have not yet been developed. In gaming disorder, an upsurge in research was observed following the inclusion of internet gaming disorder as a condition for 
Accepted manuscript of article accepted for publication in Current Addiction Reports.

further study in the DSM-5. A similar pattern is expected with the inclusion of gaming disorder in the ICD-11. It is especially timely that work is currently underway at the WHO to develop a clinical diagnostic and fully structured interview and a screening measure for gaming disorder. The availability of such valid and reliable instruments will give impetus to high quality epidemiological studies that may in turn inform future nosological efforts. Such work should in turn help advance public health, prevention and treatment efforts.

- Insert Table 1 about here -

Future studies examining possible disorders due to addictive behaviors should follow recommendations summarized in Table 1. Of note, while this article has focused on gaming disorder and internet addiction, many of the considerations may apply to a broader range of putative behavioral addictions, and such conditions warrant further consideration in separate reviews. Sample sizes should be based on power calculations that consider expected effect sizes, expected disorder rates, and analyses of subgroups. Such an approach should result in a reduction of random error. In order to reduce systematic error, a sound theoretical conceptualization is important. In addition, a clear description of the behavior under study is needed and should replace blurred concepts like internet addiction. Furthermore, sound assessment instruments which should include standardized clinical interviews are of special importance. For the purpose of data collection in large studies, fully structured and standardized interviews should be available that can be conducted by lay interviewers, which is, for example, the case with the Composite International Diagnostic Interview [36]. The development of such instruments should include validation by clinician-administered structured diagnostic interview. All studies should use measures of functional impairment to evaluate the clinical relevance of the respective condition. Moreover, systematic error may be reduced by careful consideration of recruitment procedures. Studies employing convenience samples should be avoided. Although such studies may be a useful starting 
Accepted manuscript of article accepted for publication in Current Addiction Reports.

point for examining a potentially new condition and for developing hypotheses, subsequent data should be gathered by pro-active recruitment to avoid bias related to self-selection. In addition, these samples should be large-scale and representative of the respective population under study (e.g. general population, children and adolescents, etc.) to increase generalizability. In order to improve representativeness, weighted analysis procedures may be used. However, this approach may be limited and result in diminished statistical power. It should be emphasized that weightings may be used for a limited number of sociodemographic characteristics; however, they are typically not applicable to convenience samples. Moreover, studies should be carefully designed to assess relevant confounding variables - like co-occurring disorders - in a sound manner. These variables may then be considered as covariates in statistical analyses. Finally, evidence from cross-sectional studies requires validation in longitudinal research designs to avoid systematic error such as recall bias and to permit possible causal inferences.

Recommendations outlined in this review are of special importance for the improvement of studies in the area of behavioral addictions and for networked research more generally. Using a common framework increases the potential for reliable pooled sampling and thus may lead to improved statistical power. For example, the COST (Collaboration in Science and Technology) Action "European Network for Problematic Usage of the Internet" puts special emphasis on generating well-designed studies [37] from which meaningful findings may be obtained. This and other collaborations could profit from high methodological standards and harmonization of designs. In addition, research collaborations should include a cross-cultural dimension.

Following the recommendations described above will bring the evidence of epidemiological findings of behavioral addictions to the level that is common in other areas of mental disorders. This level of evidence is needed to increase the precision and validity of considerations related to public health consequences and for developing measures to aid prevention and treatment. This process may include development of models, comparisons 
Accepted manuscript of article accepted for publication in Current Addiction Reports.

between countries or regions and monitoring of trends. For this purpose, harmonization of assessment instruments and fulfillment of high standards to reduce random and systematic error are important. We call upon researchers to apply the recommendations outlined in this review.

\section{Acknowledgements}

This publication is based upon work from COST Action CA16207 "European Network for Problematic Usage of the Internet", supported by COST (European Cooperation in Science and Technology: www.cost.eu). Marc Potenza has received support from the Connecticut State Department of Mental Health and Addiction Services, the Connecticut Mental Health Center, the Connecticut Council on Problem Gambling, and the National Center for Responsible Gaming. The funding agencies did not provide input or comment on the content of the manuscript, and the content of the manuscript reflects the contributions and thoughts of the authors and do not necessarily reflect the views of the funding agencies. Zsolt Demetrovics was supported by the Hungarian National Research, Development and Innovation Office (Grant numbers: KKP126835). Vladimir Poznyak is a staff member of the World Health Organization. The views expressed in this publication do not necessarily represent the decisions or policies of the World Health Organization.

Compliance with ethical standards

Conflict of Interest

Hans-Jürgen Rumpf, Dominique Brandt, Zsolt Demetrovics, Joël Billieux, Natacha Carragher, Matthias Brand, Henrietta Bowden-Jones, Afarin Rahimi-Movaghar, Sawitri Assanangkornchai, Renata Glavak-Tkalic, Guilherme Borges, Hae-Kook Lee, Florian

Rehbein, Naomi A. Fineberg, Karl Mann, Marc N. Potenza, Dan J. Stein, Susumu Higuchi, 
Accepted manuscript of article accepted for publication in Current Addiction Reports.

Daniel King, John B. Saunders and Vladimir Poznyak declare that they have no conflict of interest with regard to this manuscript.

Naomi Fineberg reports personal fees from Otsuka, Lundbeck, Abbott, Sun Pharma, Taylor and Francis, Elsevier; personal fees and non-financial support from RANZCP, Wiley; grants from NIHR, Wellcome; grants and non-financial support from EU, ECNP, Shire; non-financial support from BAP, WHO, CINP, ISAD, RCPsych, International College Of OC Spectrum Disorders, IFMAD, MHRA; other from Oxford University Press, all outside the submitted work.

Marc Potenza has received financial support or compensation for the following: Dr. Potenza has consulted for and advised RiverMend Health, Opiant/Lakelight Therapeutics, and Jazz Pharmaceuticals; has received unrestricted research support from Mohegan Sun Casino and grant support from the National Center for Responsible Gaming; and has consulted for legal and gambling entities on issues related to impulse control disorders.

Human and Animal Rights and Informed Consent

This article does not contain any studies with human or animal subjects performed by any of the authors.

\section{References}

1. American Psychiatric Association, editor. Diagnostic and Statistical Manual of Mental Disorders, fifth edition. Washington, D.C.: American Psychiatric Association; 2013. 2. World Health Organization. ICD-11 for Mortality and Morbidity Statistics. Mental, behavioural or neurodevelopmental disorders. World Health Organisation,. 2018. https://icd.who.int/browse11//-m/en. Accessed January 30, 2019. 
Accepted manuscript of article accepted for publication in Current Addiction Reports.

3. Rumpf HJ, Achab S, Billieux J, Bowden-Jones H, Carragher N, Demetrovics Z et al. Including gaming disorder in the ICD-11: The need to do so from a clinical and public health perspective. J Behav Addict. 2018:1-6. doi:10.1556/2006.7.2018.59.

4. ${ }^{* \star}$ Saunders JB, Hao W, Long J, King DL, Mann K, Fauth-Buhler M et al. Gaming disorder: Its delineation as an important condition for diagnosis, management, and prevention. $\mathrm{J}$ Behav Addict. 2017;6(3):271-9. doi:10.1556/2006.6.2017.039. This review outlines the evidence for incuding gaming disorder in ICD-11.

5. Baggio S, Starcevic V, Studer J, Simon O, Gainsbury SM, Gmel G et al. TechnologyMediated Addictive Behaviors Constitute a Spectrum of Related Yet Distinct Conditions: A Network Perspective (vol 32, pg 564, 2018). Psychology of Addictive Behaviors. 2018;32(6):594-. doi:10.1037/adb0000405.

6. Earp BD, Wudarczyk OA, Foddy B, Savulescu J. ADDICTED TO LOVE What Is Love Addiction and When Should It Be Treated? Philosophy Psychiatry \& Psychology. 2017;24(1):77-92. doi:10.1353/ppp.2017.0011.

7. Hing N, Russell A, Tolchard B, Nower L. Risk Factors for Gambling Problems: An Analysis by Gender. Journal of Gambling Studies. 2016;32(2):511-34. doi:10.1007/s10899-015-95488.

8. Yakovenko I, Hodgins DC. A scoping review of co-morbidity in individuals with disordered gambling. International Gambling Studies. 2018;18(1):143-72. doi:10.1080/14459795.2017.1364400.

9. Subramaniam M, Chua BY, Abdin E, Pang S, Satghare P, Vaingankar JA et al. Prevalence and Correlates of Internet Gaming Problem among Internet Users: Results from an Internet Survey. Annals Academy of Medicine Singapore. 2016;45(5):174-83.

10. Hasin D, Keyes K. The Epidemiology of Alcohol and Drug Disorders. In: Johnson BA, editor. Addiction Medicine. New York: Springer 2011. p. 23-49.

11. Brand M, Young KS, Laier C, Wolfling K, Potenza MN. Integrating psychological and neurobiological considerations regarding the development and maintenance of specific 
Accepted manuscript of article accepted for publication in Current Addiction Reports.

Internet-use disorders: An Interaction of Person-Affect-Cognition-Execution (I-PACE) model. Neurosci Biobehav Rev. 2016;71:252-66. doi:10.1016/j.neubiorev.2016.08.033.

12. Rothman. Modern Epidemiology. Boston/Toronto: Little, Brown and Company; 1986.

13. Petry NM, Stinson FS, Grant BF. Comorbidity of DSM-IV pathological gambling and other psychiatric disorders: results from the National Epidemiologic Survey on Alcohol and Related Conditions. J Clin Psychiatry. 2005;66(5):564-74.

14. Kessler RC, Hwang I, LaBrie R, Petukhova M, Sampson NA, Winters KC et al. DSM-IV pathological gambling in the National Comorbidity Survey Replication. Psychol Med. 2008;38:1351-60.

15. Fam JY. Prevalence of internet gaming disorder in adolescents: A meta-analysis across three decades. Scand J Psychol. 2018;59(5):524-31. doi:10.1111/sjop.12459.

16. Kuss DJ, Griffiths MD, Karila L, Billieux J. Internet Addiction: A Systematic Review of Epidemiological Research for the Last Decade. Curr Pharm Des. 2013. doi:CPD-EPUB55632 [pii].

17. ${ }^{\star *}$ Mihara S, Higuchi S. Cross-sectional and longitudinal epidemiological studies of Internet gaming disorder: A systematic review of the literature. Psychiatry Clin Neurosci. 2017;71(7):425-44. doi:10.1111/pcn.12532. This is a comprehensivereview on epidemiological studies in the area of gaming disorder.

18. ${ }^{* *}$ Billieux J, King DL, Higuchi S, Achab S, Bowden-Jones H, Hao W et al. Functional impairment matters in the screening and diagnosis of gaming disorder. J Behav Addict. 2017;6(3):285-9. doi:10.1556/2006.6.2017.036. This article highlights the need to consider functional impairment in behavioral addictions.

19. Király O, Nagygyörgy K, Koronczai B, Griffiths MD, Demetrovics Z. Assessment of Problematic Internet Use and Online Video Gaming. In: Aboujaoude E, Starcevic V, editors. Mental Health in the Digital Age: Grave Dangers, Great Promise New York: Oxford University Press.; 2015. p. 46-68.

20. Kuss DJ, Griffiths MD, Karila L, Billieux J. Internet addiction: a systematic review of epidemiological research for the last decade. Curr Pharm Des. 2014;20(25):4026-52. 
Accepted manuscript of article accepted for publication in Current Addiction Reports.

21. Laconi S, Rodgers RF, Chabrol H. The measurement of Internet addiction: A critical review of existing scales and their psychometric properties. Comput Human Behav. 2014;41:190-202. doi:10.1016/j.chb.2014.09.026.

22. King DL, Haagsma MC, Delfabbro PH, Gradisar M, Griffiths MD. Toward a consensus definition of pathological video-gaming: a systematic review of psychometric assessment tools. Clin Psychol Rev. 2013;33(3):331-42. doi:S0272-7358(13)00005-6 [pii] 10.1016/j.cpr.2013.01.002.

23. Pearcy BTD, Roberts LD, McEvoy PM. Psychometric Testing of the Personal Internet Gaming Disorder Evaluation-9: A New Measure Designed to Assess Internet Gaming Disorder. Cyberpsychology Behavior and Social Networking. 2016;19(5):335-41. doi:10.1089/cyber.2015.0534.

24. Vadlin S, Aslund C, Nilsson KW. Development and content validity of a screening instrument for gamingaddiction in adolescents: The Gaming Addiction Identification Test (GAIT). Scand J Psychol. 2015;56(4):458-66. doi:10.1111/sjop.12196.

25. Pontes HM, Kiraly O, Demetrovics Z, Griffiths MD. The Conceptualisation and Measurement of DSM-5 Internet Gaming Disorder: The Development of the IGD-20 Test. PLoS ONE. 2014;9(10):9. doi:10.1371/journal.pone.0110137.

26. Pontes HM, Griffiths MD. Measuring DSM-5 internet gaming disorder: Development and validation of a short psychometric scale. Computers in Human Behavior. 2015;45:137-43. doi:10.1016/j.chb.2014.12.006.

27. Kiraly O, Sleczka P, Pontes HM, Urban R, Griffiths MD, Demetrovics Z. Validation of the Ten-Item Internet Gaming Disorder Test (IGDT-10) and evaluation of the nine DSM-5 Internet Gaming Disorder criteria. Addict Behav. 2017;64:253-60.

doi:10.1016/j.addbeh.2015.11.005.

28. Lemmens JS, Valkenburg PM, Gentile DA. The Internet Gaming Disorder Scale. Psychol Assess. 2015;27(2):567-82. doi:10.1037/pas0000062. 
Accepted manuscript of article accepted for publication in Current Addiction Reports.

29. Zadra S, Bischof G, Besser B, Bischof A, Meyer C, John U et al. The association between Internet addiction and personality disorders in a general population-based sample. $J$ Behav Addict. 2016;5(4):691-9. doi:10.1556/2006.5.2016.086.

30. Maraz A, Kiraly O, Demetrovics Z. Commentary on: Are we overpathologizing everyday life? A tenable blueprint for behavioral addiction research The diagnostic pitfalls of surveys: If you score positive on a test of addiction, you still have a good chance not to be addicted. Journal of Behavioral Addictions. 2015;4(3):151-4. doi:10.1556/2006.4.2015.026.

31. Jeong H, Yim HW, Lee SY, Lee HK, Potenza MN, Kwon JH et al. Discordance between self-report and clinical diagnosis of Internet gaming disorder in adolescents. Scientific Reports. 2018;8. doi:10.1038/s41598-018-28478-8.

32. Bethlehem J. Selection Bias in Web Surveys. International Statistical Review. 2010;78:161-88. doi:10.1111/j.1751-5823.2010.00112.x.

33. Greenacre ZA. The Importance of Selection Bias in Internet Surveys. Open Journal of Statistics. 2016;6:ID:67313. doi:10.4236/ojs.2016.63035.

34. Rumpf HJ, Bischof G, Hapke U, Meyer C, John U. Studies on natural recovery from alcohol dependence: sample selection bias by media solicitation? Addiction. 2000;95(5):76575.

35. ${ }^{*}$ Starcevic V, Billieux J, Schimmenti A. Selfitis and behavioural addiction: A plea for terminological and conceptual rigour. Aust N Z J Psychiatry. 2018;52(10):919-20. doi:10.1177/0004867418797442. This article highlights to be careful in proposing behavioral addictions.

36. Robins LN, Wing J, Wittchen HU. The Composite International Diagnostic Interview: an epidemiological instrument suitable for use in conjunction with different diagnostic systems and in different cultures. Arch Gen Psychiatry. 1988;45:1069-77.

37. Fineberg NA, Demetrovics Z, Stein DJ, loannidis K, Potenza MN, Grunblatt E et al. Manifesto for a European research network into Problematic Usage of the Internet. Eur Neuropsychopharmacol. 2018;28(11):1232-46. doi:10.1016/j.euroneuro.2018.08.004. 
Accepted manuscript of article accepted for publication in Current Addiction Reports. 
Accepted manuscript of article accepted for publication in Current Addiction Reports.

Table 1: Recommendations for future studies

\begin{tabular}{|c|c|}
\hline Reducing random error & Reducing systematic error \\
\hline $\begin{array}{l}\text { - Sample sizes based on power } \\
\text { calculations according to the } \\
\text { expected magnitude of effects } \\
\text { - Sample sizes based on power } \\
\text { calculations according to the } \\
\text { expected disorder rate } \\
\text { Sample sizes based on power } \\
\text { calculations according to sub- } \\
\text { populations }\end{array}$ & $\begin{array}{l}\text { - Sound theoretical conceptualization } \\
\text { - Sound assessment based on } \\
\text { agreed-upon criteria and rigorous } \\
\text { and reliability } \\
\text { - Standardized clinical diagnostic } \\
\text { interviews, fully structured interviews } \\
\text { for lay administration, and screening } \\
\text { instruments } \\
\text { - Avoidance of selection bias by pro- } \\
\text { active recruitment } \\
\text { - Longitudinal studies to permit } \\
\text { possible causal inferences } \\
\text { - Sound assessment of confounding } \\
\text { variables } \\
\text { generalizability }\end{array}$ \\
\hline
\end{tabular}

